\title{
Optimization of a three-layer rotary generator using genetic algorithm to minimize fuel consumption
}

\author{
Hamid Abroshan ${ }^{1, *},{ }^{*}$ Mahdi Goodarzi ${ }^{1}$ \\ ${ }^{1}$ Power Generation Department, Niroo Research Institute (NRI), P.O.BOX: 14665/517, Tehran, Iran. Phone: +98 9355128117
}

\begin{abstract}
Reduction of fuel consumption in power plants is an important issue due to their high rate of fuel usage. In the present article, this was done by optimizing rotary regenerator which have a great role in recovering thermal energy in power stations. Heat transfer and pressure drop through 13 popular flow passages of power plant's rotary regenerators were obtained by CFD simulations. The outcomes were used in a mathematical model of the rotary air heater by considering air leakages. The model was capable of distinguishing between different heating surfaces. Then it was used for optimizing a regenerator by genetic algorithm. Rotational speed and dimensions of all three layers (hot end, intermediate layer, and cold end) were optimized to achieve the highest fuel saving. These dimensions were: hydraulic diameters, heating profile type, and length of each layer. Results showed that redesigning these parameters to the optimal values leads to saving of $443 \mathrm{~kg}$ of natural gas per hour for one regenerator. A 10 meter regenerator also had the highest reduction in fuel consumption $(660 \mathrm{~kg} / \mathrm{hr})$. Finally, the influence of air and hot gas temperatures, and air mass flow rate on fuel saving and optimum values of design parameters was discussed.
\end{abstract}

\section{ARTICLE HISTORY}

Revised: $17^{\text {th }}$ Sept 2019

Accepted: $17^{\text {th }}$ Sept 2019

\section{KEYWORDS}

Rotary regenerator;

heat wheel;

waste heat recovery;

optimization.

\section{INTRODUCTION}

Rotary regenerators, also known as Ljungstroms, Rotary Air Heaters (RAH) or heat wheels, have played a critical role in waste heat recovery during past decades. They were used widely in thermal power plants and HVAC applications. In steam power plants, they improve the thermal efficiency of a boiler by capturing a portion of heat content from flue gas before exhausting to atmosphere and then give it to the fresh air. This preheating of the air entering the burners (for example from $30^{\circ} \mathrm{C}$ to $300^{\circ} \mathrm{C}$ ) is identical to a significant amount of fossil fuel saving. Warren [1] discussed the history, principal design features, and reliability of RAHs and confirmed a minimum reduction of 7.9 to $21.4 \%$ in power plants fuel consumption base on the experimental results. The main part of a rotary regenerator heat exchanger is a cylindrical porous media named matrix or rotor. The matrix rotates slowly between two hot and cold streams flowing continuously in opposite directions. The energy transfer between two streams accomplished by heat transfer from hot gases to solid matrix walls and then from walls to the cold air. Rotary regenerators are simple and suitable for gas to gas heat transfer when a little mixing of two streams is acceptable. But the main disadvantage of rotary air heaters is the unavoidable leakage of cold stream (air) to hot stream (gas) which influences their performance negatively.

Many researchers have paid attention to heat wheels in the past years through numerical, analytical or experimental studies [2-18]. Most of attempts in this area were focused on modeling rotary regenerators to calculate their effectiveness, outlet temperatures, matrix temperature distribution, and leak flows. Besides, the main focus of many articles were on two areas: (1) regenerators with HVAC application that are usually smaller and often have faster rotation speed and (2) Ljungstroms with power plant usage that are bigger and have slower rotational speed. In the following paragraphs, some of the researches will be addressed in order of the dimension of their models (i.e. zero, one, two and three dimensional).

Mathematical modeling was the most used method in the literature. These zero dimension models often delivered a good estimate of overall parameters such as effectiveness and outlet temperatures. A model by concept of $N T U-\varepsilon$ was developed and the results were compared to experimental data showing a $\pm 5 \%$ deviation in the heat transfer effectiveness [14]. There are many other attempts of zero dimensional modeling of RAHs in the literature $[8,13]$. In an article, three matrix surfaces (monolith, woven screen, and spherical particles) were compared to each other from pressure drop and thermal effectiveness point of view [5]. It was concluded by their mathematical modeling that a large diameter regenerator with a high porosity woven screen or monolith (which had a significantly smaller pressure drop) is preferable. In another study [17], a mathematical method was introduced by proposing a Nusselt number correlation. The correlation was developed to take into account various cross sections (circular, square, triangular, rectangular, and parallel plates) at laminar flow regime. An analytical algorithm was also developed to model a rotary regenerator by considering flow leakage [15]. Although the model is unclear (for instance how the heat transfer coefficient was calculated), a regenerator was divided into two layers (hot end and cold end) which is a good approach.

One dimensional approach to a rotary regenerator brought some extra capability to a regenerator model. For example, the heat transfer rate per unit of frontal surface area was maximized by adjusting the length and porosity of a matrix [4]. 
Authors assumed a constant Nusselt number through a regenerator built from parallel channels. Medium-small size rotary regenerators were also studied numerically to check the effect of matrix porosity on total heat transfer for a fixed pressure drop or pumping power [11]. Authors utilized a correlation for heat transfer assuming a triangular passage for matrix. It was found that an optimum porosity value exists which increases by decreasing pumping power. In another investigation a Nusselt number was used for developing flow inside corrugated sinusoidal channels [16]. The one dimensional method is valuable and could be used to find out transient solutions due to its high calculation speed [3, 19]. However, transient solutions even could be achieved by zero dimensional approaches [6]. Two and three dimensional analyses may be used only if more details are expected.

Two dimensional models can give temperature distribution along a regenerator but they also use a simple correlation for all types of heating surfaces. For example in an article, a simple correlation was used for accounting the heat transfer coefficient which was required in a transient 2D modeling of a desiccant wheel [10]. Nevertheless, 3D simulations have been more welcomed comparing to $2 \mathrm{D}$ models. For instance, a rotary regenerative heat exchanger in flue gas desulfurization was simulated by 3D-CFD using a porous media approach [12]. For calculating the heat transfer coefficient, laminar flow inside a single corrugated sinusoidal channel was firstly modeled by CFD. Another 3D-CFD simulation of a rotary air preheater in a $300 \mathrm{MW}$ power station was conducted by assuming a CU heating profile [9]. Authors validated flue gas outlet temperature with measured data $\left(1.2^{\circ} \mathrm{C}\right.$ deviation) and design values $\left(7.7^{\circ} \mathrm{C}\right)$. Bearing in mind that they ignored flow leakage, it indicates that a CFD simulation (with methods and assumptions they used) may over predicts the heat transfer in a RAH. In another research [2], the authors demonstrated by a 3D numerical method in laminar regime that circular and square passages have a better overall system performance (heat transfer to pumping power) comparing to a triangular passage. Temperature distribution over a rotary regenerator was obtained in another work by CFD modeling and considering the matrix as a porous media [7].

One of the most attractive goals of modeling rotary regenerators is to optimize them. An optimized rotary regenerator was obtained with at least $26.5 \%$ less weight while thermal outputs remained unchanged [20]. Ghodsipour and Sadrabeli [21] used a numerical method based on $N T U-\varepsilon$ by calculating the heat transfer and friction factor along a regenerator using a correlation proposed by Kays \& London [22] for three matrix surfaces including rectangle, square and triangle. A regenerator with randomly staked woven screen matrix was modeled by $N T U-\varepsilon$ implementing empirical correlations for heat transfer coefficient and friction factor [23]. Then six design variables (frontal area, matrix rod diameter, matrix thickness, rotational speed, split, and porosity) were optimized by a self-learning algorithm to maximize the regenerator effectiveness and minimize the pressure drop simultaneously.

One of the main drawbacks of zero, one and two dimensional methods is that they use a simple correlation to calculate Nusselt number inside the regenerator. In fact, they do not distinguish between various heating surfaces, no matter the regenerator is built from CU profiles or DU profiles. The difference between flow passages on performance of a RAH was considered in a few articles $[2,5,17,21]$. These articles studied heating surfaces such as circular, rectangular, triangular, square, parallel plates, monolith, woven screens, and spherical particles. Almost all of them used the correlations for laminar flow. However, some investigations have used CFD simulation to find out the heat transfer and pressure drop in a rotary regenerator $[9,12]$. But they have modeled only one heating surface. Many other articles have studied different geometries in heat exchangers in general [24-26]. But their outcomes could not be directly used for thermal wheels; or they only have focused on pressure drop of one geometry [27]. In fact, there are a small number of research attempts applicable to power plants' RAHs that have compared various passages via CFD simulation. For example, corrugated plates with different aspect ratios and inclination angles were studied numerically at turbulent regime [28]. It was suggested that an aspect ratio equal to 1.125 with highest angle can lead to the best heat transfer considering pressure drop. In another attempt, five types of flow passages were simulated numerically [29]. Three of them are the same as our investigation (notched flat, flat notched crossed, and corrugated undulated).

Regarding above descriptions, modeling a rotary regenerator has been well developed. But authors did not found any research which considers various heating surfaces in modeling the rotary regenerators of power stations (i.e. by taking into account common surfaces in Ljungstrums). This gap was detected in an industrial project, where optimum heating surface was requested. Therefore, the main objective of this research was to optimize a rotary regenerator by considering different geometrical parameters and especially the heating surface types. The other motivation for conducting this research was to study three common layers in power plant's regenerators (hot end, intermediate, and cold end) separately. This helps us to achieve a better optimal RAH by allocating a specific geometry to each layer.

\section{METHODS}

This study involves three steps of calculations, each of them has a different methodology. These steps are CFD modeling of various profiles, mathematical modeling of a RAH, and optimization of the RAH.

\section{CFD Modeling of Profiles}

The profiles which have been studied are: Notched Flat (NF), Corrugated Plate (CP), Corrugated Undulated (CU), Double Undulated (DU), and Flat Notched Crossed (FNC). Figure 1 shows each profile and Table 1 demonstrates their main geometrical data. The parameters $\mathrm{P}$ and $\mathrm{H}$ are illustrated in Figure 1 for NF and corrugated plates and $\mathrm{S}$ is the curve length between start and end points of each pitch. The inclination angle of the corrugated, undulated, and notched elements is another parameter for all profiles except NF. The NF profile has a simple geometry and usually is used on the cold end of the RAH to slow down the fouling and corrosion. The inclination angle is measured from the flow direction. For the 
corrugated elements in CP profile, three angles of 0, 20, and 30 degrees and for the undulated elements in CU and DU and notches in FNC profile, three angles of 20, 30, and 50 degrees have been considered. Besides, the inclination angles of two undulated elements in DU and two flat notched elements in FNC profile are transverse.

To simulate the flow and heat transfer within the heat exchanger, the governing equations (continuity, momentum, and energy) which are 5 equations containing 5 unknowns (velocity in 3 directions of $\mathrm{x}$, y, and $\mathrm{z}$, pressure, and temperature) were solved. For solving these equations, domain was first meshed by tetrahedral mesh. In Figure 2, a sample of meshing is presented for DU profile. The steady, incompressible, and turbulent air flow in the computational domain was expressed by Navier-Stokes equations. A commercial software (FLUENT) was used for simulation while a $k-\varepsilon$ method was chosen for turbulence modeling. This turbulence model reproduced velocity of the fluid flowing inside a rotary air heater with rectangular profiles quite accurately comparing experimental measurements [27]. After solution of these equations, friction factor and convection heat transfer coefficient were calculated.

To be ensure about grid independency of the CFD simulations, number of computational cells was increased from 160,000 to $6,800,000$. Grids were refined near walls and wherever a sharp gradient of velocity or temperature was detected. In more complex profiles (e.g. CU), the heat transfer and pressure drop indicators were not changed significantly for a grid number larger than 3,333,184 (Figure 3). Therefore, a grid number almost equal to 3 million cells was employed for all profiles.

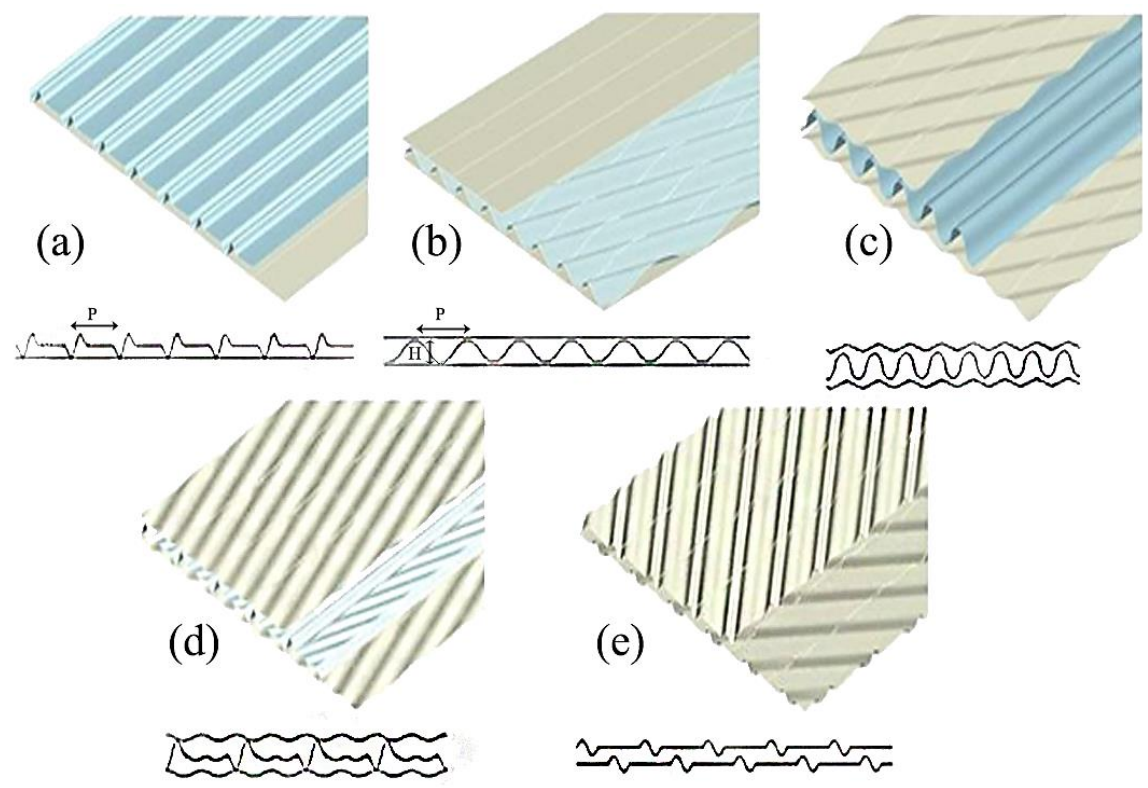

Figure 1. Geometry of considered profiles (a) NF, (b) CP, (c) CU, (d) DU, and (e) FNC.

Table 1. Geometric dimensions of the profiles.

\begin{tabular}{|c|c|c|c|c|c|c|}
\hline \multicolumn{2}{|c|}{ Geometry } & $\mathrm{P}(\mathrm{mm})$ & $\mathrm{H}(\mathrm{mm})$ & $\mathrm{S}(\mathrm{mm})$ & $\mathrm{P} / \mathrm{H}$ & $\mathrm{D}_{\mathrm{h}}(\mathrm{mm})$ \\
\hline \multicolumn{2}{|l|}{ NF } & 30 & 20 & 53.26 & 1.5 & 18.43 \\
\hline \multicolumn{2}{|l|}{$\mathrm{CP}$} & 20 & 5.8 & 23.85 & 3.45 & 7.11 \\
\hline \multirow{3}{*}{$\mathrm{CU}$} & Corrugated & 22 & 13.13 & 36.98 & 1.68 & \multirow{2}{*}{13.72} \\
\hline & Undulated & 22 & 3.65 & 23.23 & 6.03 & \\
\hline & Notched & 30 & 20 & 52.81 & 1.5 & 21.58 \\
\hline \multirow[b]{2}{*}{ DU } & Undulated 1 & 20 & 2.5 & 20.8 & 8 & \\
\hline & Undulated 2 & 35 & 4 & 36.18 & 8.75 & \\
\hline \multicolumn{2}{|c|}{ FNC } & 20 & 10 & 29.58 & 2 & 16 \\
\hline
\end{tabular}

In Figure 1 and Table $1, P$ refers to transverse distance between repeated patterns in a basket $(\mathrm{m}), H$ is height of a profile (m), $S$ stands for Curve length of profile (m), and $D_{h}$ is hydraulic diameter of profile (m). 


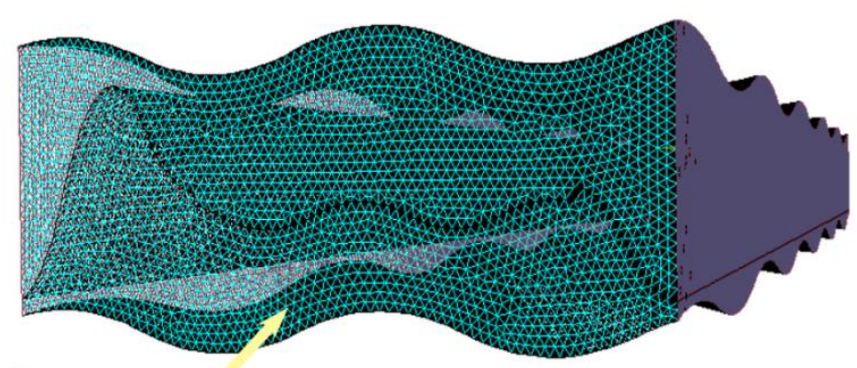

$z=\quad$ Inlet Section

Figure 2. Tetrahedral mesh used for a DU profile

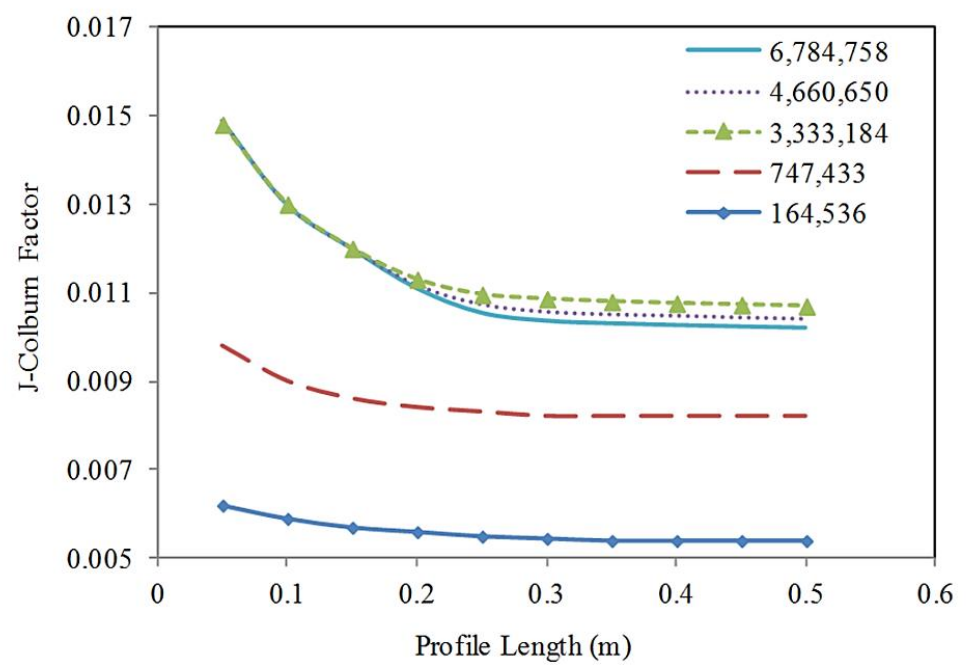

Figure 3. Mesh independency of the CFD simulation for CU30 (Re=6600).

In general, the convective heat transfer coefficient can be calculated by surface heat flux and its temperature difference with a contractual reference temperature like far field temperature or mixed mean temperature. In the numerical solutions performed here, the surface temperatures considered constant and the cross section mean temperature has been used as reference temperature to calculate the heat transfer coefficient.

Thus after obtaining the mean flow temperature at inlet and outlet cross sections $\left(T_{m, i}\right.$ and $\left.T_{m, o}\right)$ from CFD simulation, the convective heat transfer coefficient was calculated by [30]:

$$
\bar{h}=\frac{\dot{m} c_{p}}{P_{\text {rem }} L} \ln \frac{T_{s}-T_{m, i}}{T_{s}-T_{m, o}}
$$

where $\dot{m}$ stands for mass flow rate $\left(\mathrm{kg} . \mathrm{s}^{-1}\right), c_{p}$ for specific heat capacity at constant pressure $\left(\mathrm{J} \mathrm{kg}^{-1} \cdot \mathrm{C}^{-1}\right), T_{s}$ for surface temperature $\left({ }^{\circ} \mathrm{C}\right), \bar{h}$ for mean convective heat transfer coefficient $\left(\mathrm{W} . \mathrm{m}^{-2} \cdot \mathrm{C}^{-1}\right.$ ), while $L$ and $P_{\text {rem }}$ are profile's length (m) and wetted perimeter of profile $(\mathrm{m})$, respectively. Then the dimensionless Nusselt number $(\mathrm{Nu})$ can be calculate using fluid properties:

$$
N u=\bar{h} D_{h} / k
$$

where $k$ is thermal conductivity of fluid $\left(\mathrm{J} \cdot \mathrm{m}^{-1} \cdot \mathrm{C}^{-1}\right)$. For calculation of the friction factor $(f)$, mean pressure in inlet and outlet sections of a profile were derived from CFD and their difference $(\Delta P)$ was used as below:

$$
\mathrm{f}=\frac{\Delta \mathrm{PD}_{\mathrm{h}}}{\frac{1}{2} \rho \mathrm{U}^{2} \mathrm{~L}}
$$

Parameter $U$ refers to velocity of fluid entering the profile $\left(\mathrm{m} \cdot \mathrm{s}^{-1}\right)$ and $\rho$ is density of fluid $\left(\mathrm{kg} \cdot \mathrm{m}^{-3}\right)$. 


\section{RAH Modeling}

An iterative method has been used to calculate the heat exchanger efficiency. First the ideal efficiency of heat exchanger (without leakages) was calculated using a correlation given by Kays and London [22]. Then the pressure loss in different layers of the RAH was calculated and the values of leakages were acquired from relations given by Shah and Sekulic [31] and Skiepko [32]. In the next step, values of the energy losses by these leakages were computed and then subtracted from the total heat transfer rate of the ideal regenerator. So the actual heat transfer rate could be obtained. Using this actual heat transfer rate, the actual efficiency and outlet temperatures of each stream were calculated. In a new iteration, after updating the properties of fluids, the effect of leakages flow rates on inlet mass flow rates was considered. The iterative process continued until convergence of the results.

\section{Ideal RAH}

The correlation used to calculate the ideal efficiency of a rotary regenerative heat exchanger is based on the $\varepsilon-N T U$ method. According to this method the efficiency of a heat exchanger $(\varepsilon)$ is defined as the ratio of actual heat transfer rate $(q)$ to maximum possible heat transfer rate $\left(q_{\max }\right)$ :

$$
\varepsilon=\frac{\mathrm{q}}{\mathrm{q}_{\max }}=\frac{\mathrm{C}_{\mathrm{h}}\left(\mathrm{T}_{\mathrm{h}, \mathrm{i}}-\mathrm{T}_{\mathrm{h}, \mathrm{o}}\right)}{\mathrm{C}_{\min }\left(\mathrm{T}_{\mathrm{h}, \mathrm{i}}-\mathrm{T}_{\mathrm{c}, \mathrm{i}}\right)}=\frac{\mathrm{C}_{\mathrm{c}}\left(\mathrm{T}_{\mathrm{c}, \mathrm{o}}-\mathrm{T}_{\mathrm{c}, \mathrm{i}}\right)}{\mathrm{C}_{\min }\left(\mathrm{T}_{\mathrm{h}, \mathrm{i}}-\mathrm{T}_{\mathrm{c}, \mathrm{i}}\right)}
$$

where $T_{h, i}, T_{h, o}, T_{c, i}$ and $T_{c, o}$ are temperatures of hot stream at inlet and outlet and temperatures of cold stream at inlet and outlet of the RAH, respectively. $C_{h}$ stands for heat capacity of hot stream, $C_{c}$ for heat capacity of cold stream, and $C_{\min }$ refers to Lower value of $C_{c}$ and $C_{h}$. In this method, the efficiency of rotary regenerator is a function of four nondimensional parameters which are defines as below:

$$
\begin{gathered}
\text { NTU }=\frac{\mathrm{U}_{\text {overall }} \mathrm{A}}{\mathrm{C}_{\min }}=\frac{1}{\mathrm{C}_{\min }}\left[\frac{1}{1 /(\overline{\mathrm{h}} \mathrm{A})_{\mathrm{h}}+1 /(\overline{\mathrm{h}} \mathrm{A})_{\mathrm{c}}}\right] \\
\mathrm{C}^{*}=\mathrm{C}_{\min } / \mathrm{C}_{\max } \\
\mathrm{C}_{\mathrm{r}}^{*}=\mathrm{C}_{\mathrm{r}} / \mathrm{C}_{\min } \\
(\mathrm{h} \mathrm{A})^{*}=\frac{(\overline{\mathrm{h}} \mathrm{A}) \text { on the } \mathrm{C}_{\min } \text { side }}{(\overline{\mathrm{h}} \mathrm{A}) \text { on the } \mathrm{C}_{\max } \text { side }}
\end{gathered}
$$

$N T U$ is number of heat transfer units, $U_{\text {overall }}$ is the overall heat transfer coefficient, $A$ is heat transfer area, $C_{\max }$ is higher value of $C_{c}$ and $C_{h}, C^{*}$ is the ratio of $C_{\min }$ to $C_{\max }, C_{r}^{*}$ is heat capacity rate ratio of RAH, and $C_{r}$ is heat capacity rate of solid material of RAH which can be calculated by $M_{\text {met. }} . C_{m e t} . N / 60$. Here, $M_{m e t}$ stands for mass of solid material of RAH (kg), $C_{m e t}$ for heat capacity of solid material of RAH, and $N$ for RAH's rotational speed in rpm. Heat transfer coefficients were calculated using outcomes of CFD simulation (Equation. (1)). An empirical correlation was suggested for computing the effect of $C_{r}^{*}[22]$ :

$$
\varepsilon=\varepsilon_{\mathrm{cf}}\left[1-\frac{1}{9\left(\mathrm{C}_{\mathrm{r}}^{*}\right)^{1.93}}\right]
$$

where $\varepsilon_{c f}$ is the counter flow heat exchanger efficiency:

$$
\varepsilon_{\mathrm{cf}}= \begin{cases}\frac{1-\exp \left[-\mathrm{NTU}\left(1-\mathrm{C}^{*}\right)\right]}{1-\mathrm{C}^{*} \exp \left[-\mathrm{NTU}\left(1-\mathrm{C}^{*}\right)\right]} & \mathrm{C}^{*}<1 \\ \frac{\mathrm{NTU}}{1+\mathrm{NTU}} & \mathrm{C}^{*}=1\end{cases}
$$

For gaseous heat exchangers the sum of the flow pressure drops as it moves through the heat exchanger could be summarized as friction between walls and moving fluids and also losses occur because of expansions and contractions in fluid motion in the flow path. In general the core friction term is the dominant term and almost includes $90 \%$ of total pressure drop in gaseous heat exchangers [31]. The entrance effect results in pressure loss and the exit effect in most cases represents a pressure rise; thus the net effect of entrance and exit pressure losses is usually compensating and can be neglected. So the pressure loss in a RAH was written as below to take into account only momentum and core friction effects:

$$
\Delta \mathrm{P}=\frac{\mathrm{G}^{2}}{2 \rho_{\mathrm{i}}}\left[\left(1+\sigma^{2}\right)\left(\frac{\rho_{\mathrm{i}}}{\rho_{\mathrm{o}}}-1\right)+f \frac{2 \mathrm{~L}}{\mathrm{D}_{\mathrm{h}}} \rho_{\mathrm{i}}\left(\frac{1}{\rho}\right)_{\mathrm{m}}\right]
$$


where $\sigma$ is the matrix porosity, $G$ is the fluid mass velocity based on minimum free-flow area $\left(\mathrm{kg} \cdot \mathrm{m}^{-2}\right), L$ is length of layer, and $\rho_{i}, \rho_{o}$ and $\rho_{m}$ stand for the fluid density at inlet section, outlet section and the mean value of density along RAH. Using above equation, both the hot and cold streams' pressure drops are computable and by knowledge of inlet pressures, the exit and middle pressures can be computed. These pressures are needed later in calculation of pressure leakage quantities.

\section{Considering leakage effects}

Leaking the cold fluid to hot flow is an inherent characteristic of a rotary airheater. This is due to pressure difference between cold and hot streams, and carrying over the trapped fluid inside baskets for the rotational movement. Pressure leakages usually take place at the inlet and outlet areas where there is a gap between the rotor and casing. Radial sealing try to prevent mixing the cold and hot flows at entrance and exit sections. Axial sealing has the role of closing the passages which flow prefer to choose them instead of going through matrix that have higher flow resistance. Another sealing is for preventing the circumference escape of cold (high pressure) fluid into hot fluid [33].

All types of leakages should be calculated and then their influences on the ideal efficiency of the airheater should be considered. In this study, seven leakages were calculated: (1) hot end radial leakage, (2) cold end radial leakage, (3) hot side circumferential leakage, (4) cold side circumferential leakage, (5) axial leakage, (6) carry over leakage of air, and (7) carry over leakage of gas. Some of these leakages result in one or more of these consequences: decreasing RAH's efficiency, wasting the heat, and extra work of fan. These leakages are illustrated in Figure 4.

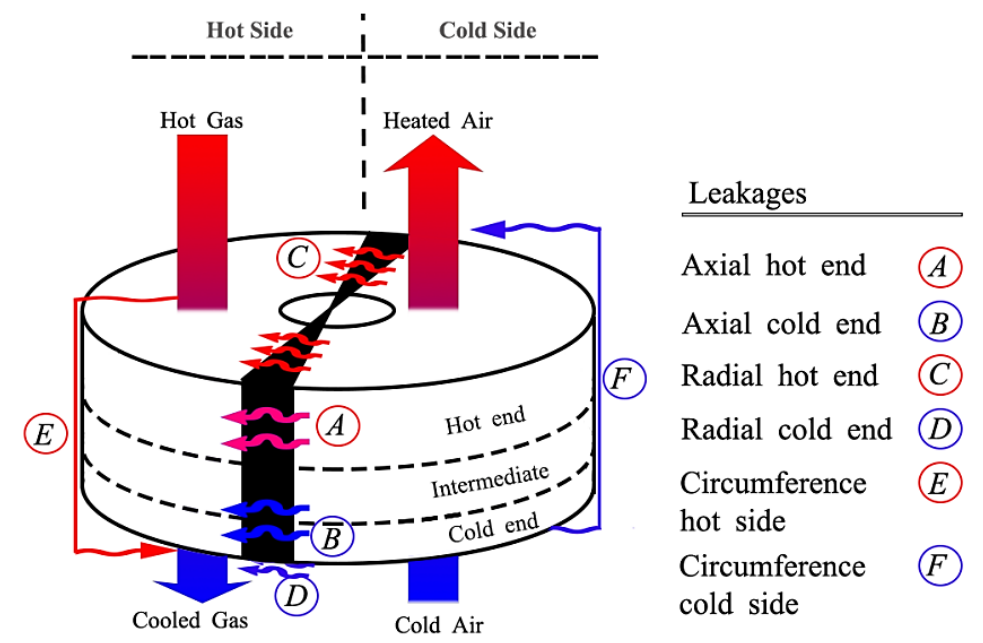

Figure 4. All types of leakages in a rotary regenerator (except carry over leakage).

To obtain a mathematical model for determination of flow of fluids through sealing system, the method introduced by Skiepko [32] has been used. According to this method, the thermodynamic process of flow through seals is supposed to be isentropic, so the pressure leakage stream through seals can be measured using Bernoulli and continuity equations supplemented with thermodynamic relations for gas flow through the leakage area. The formula driven in this manner for a specific leakage mass flow rate $\left(\dot{m}_{\text {seal }}\right)$ is governed by the coefficient of discharge $\left(C_{d}\right)$ which would be determined experimentally:

$$
\dot{\mathrm{m}}_{\text {seal }}=\mathrm{C}_{\mathrm{d}} \mathrm{A}_{\mathrm{o}, \mathrm{s}} \mathrm{Y} \sqrt{2 \rho \Delta \mathrm{P}}
$$

where $A_{o, s}$ is seal clearance flow area and $Y$ refers to expansion factor through the seal. Here, it was assumed that $Y=1$ and $C_{d}=0.8$ based on data given by Migai [34]. To determine the carry over leakage mass flow rate, this formula was used:

$$
\dot{m}_{c o}=A_{f r}\left(\frac{N}{60}\right) \rho_{\mathrm{m}}\left[\sum_{i i=1}^{n}\left(L_{i i} \sigma_{i i}\right)+\Delta L\right]
$$

In Equation. (13), $A_{f r}$ is frontal area of rotor, $\Delta L$ is height of radial seals attached to the rotor, $n$ is number of layers of RAH, while $\sigma$ and $L$ are matrix porosity and length of each layer.

\section{Optimization}

Fuel saving due to preheater usage has been spotted as the optimization objective function so that the effect of efficiency and pressure drop could be applied simultaneously. The fan work required for flowing the air and gas through the RAH was calculated based on pressure drop in hot and cold sides by considering the effects of leakages. Keeping in mind the fact that the energy consumption by a fan $\left(W_{f a n}\right)$ is in electrical form, it is rational to divide it by the net energy 
efficiency of the power plant $(\eta)$. So it could be comparable with thermal energy recovered by the RAH $\left(Q_{r e c}\right)$. Therefore, by assuming the healing value of natural gas equal to $45391 \mathrm{KJ} / \mathrm{kg}$, the function which should be maximized is:

$$
\text { Objective Function }=3600 \times \frac{\left(Q_{\text {Rec }}-W_{\text {fan }} / \eta\right)}{4.5391 \times 10^{7}}
$$

This function computes the mass of saved fuel in one hour of full load operation. Using this parameter, it will be possible to implement a single objective optimization instead of multi objective optimization. The objective function was maximized by finding the best rotational speed, and some geometrical parameters (hydraulic diameter, profile type and its inclination angle) for hot end, intermediate, and cold end layers. Further optimizations were carried out by considering length of each layer (cold end, intermediate and hot end) and also outer diameter of the RAH.

A Genetic algorithm was used to find the optimum values by means of MATLAB. Population size was changed to find the best performance. In most cases, a population size was good enough when it was in the range of 9-13 times of number of design variables. Range of design parameters assumed to be 1-100 mm for hydraulic diameters, 0.1-4 m for length of layers, and 0.1-20 rpm for rotational speed. In addition, as mentioned earlier, 13 different profiles were considered in this study.

For the corrugated elements in CP profile, three angles of 0, 20, and 30 degrees and for the undulated elements in CU and DU and notches in FNC profile, three angles of 20,30, and 50 degrees have been used. The inclination angle is measured from the flow direction.

\section{RESULTS AND DISCUSSION}

\section{Comparing Various Profiles}

As was mentioned in the introduction, each heating surface has a specific heat transfer and flow resistance characteristics. Finding these specifications was an important part of this research. The heating profiles involved in this article are: corrugated plate (CP), notched flat (NF), corrugated undulated (CU), double undulated (DU), and flat notched cross (FNC). Heat transfer coefficient and pressure drop were found based on the CFD simulation. Results are illustrated in Figure 5 by comparing the ratio of $N u / f^{1 / 3}$ for each profile. Using this parameter makes it easier to find out about the balance between heat transfer and pressure drop characteristics of profiles at a glance. Although the CP, CU, DU, and FNC profiles were modeled for three different inclination angles, the CFD simulation results are presented only for $30^{\circ}$ to minimize the obscurity and complexity of Figure 5. It is clear that CU30, FNC30 and DU30 are superior in low Reynolds numbers (the common range for most of RAHs). In higher Reynolds the performance of FNC30 dropped dramatically. From heat transfer point of view, CU30 and then DU30 significantly performed better. But a lower pressure drop for FNC30 made it competitive at low Reynolds numbers.

\section{CFD Results Validation}

As was mentioned in the introduction, few articles have compared the effectiveness of various heating surfaces of rotary regenerators. However, some of them have unusable outcomes. For example, it was claimed that FNC has the highest efficiency [29]. The main reason for achieving a small efficiency for a CU comparing to FNC is that authors computed heat and flow for a straight CU. While the main benefit of these profiles is their high level of mixing caused from both wavy plates and inclination angle. So it is important to check the validation of CFD results both quantitatively and qualitatively.

To find the accuracy of CFD simulations, they were compared to available experimental data. An experiment which is comparable with studied profiles was done by Sastiek [35]. He measured and calculated the heat transfer coefficient of some corrugated plates. A combination of his $\mathrm{CP}$ and US geometries (CP/US) is identical to our CU profile. A comparison of simulation results and experimental data is illustrated at Figure 6 for three different undulated angles. In another published paper, experimental data for a double undulated profile with and undulated angle equal to $30^{\circ}$ is presented [18]. A comparison between the numerical simulation and their experimental results is shown in Figure 7. Of course, the experimental data which were expressed by Colburn j-factor (a common method of presenting the heat transfer characteristics of fixed and rotary regenerators [36]) were converted to Nusselt number. 


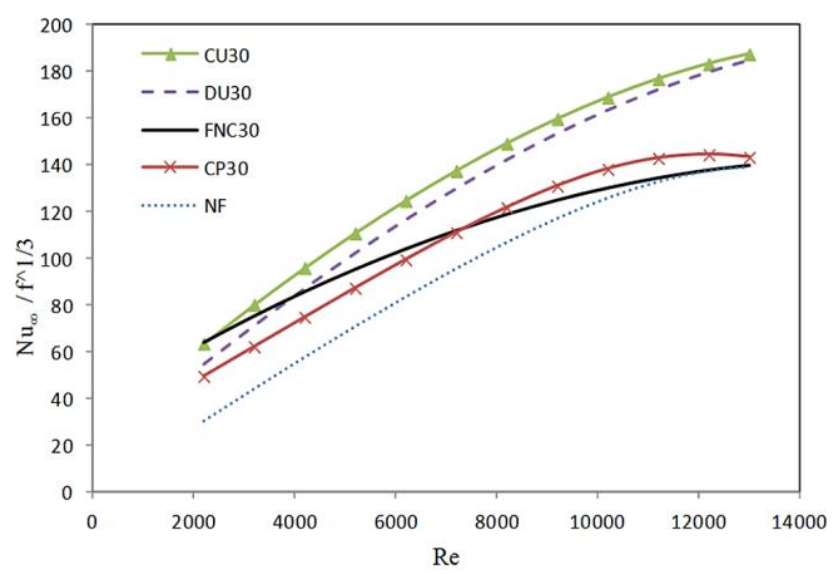

Figure 5. Fully developed $\left(\mathrm{Nu} / \mathrm{f}^{1 / 3}\right)$ for five profiles from $\mathrm{CFD}$ simulation results.

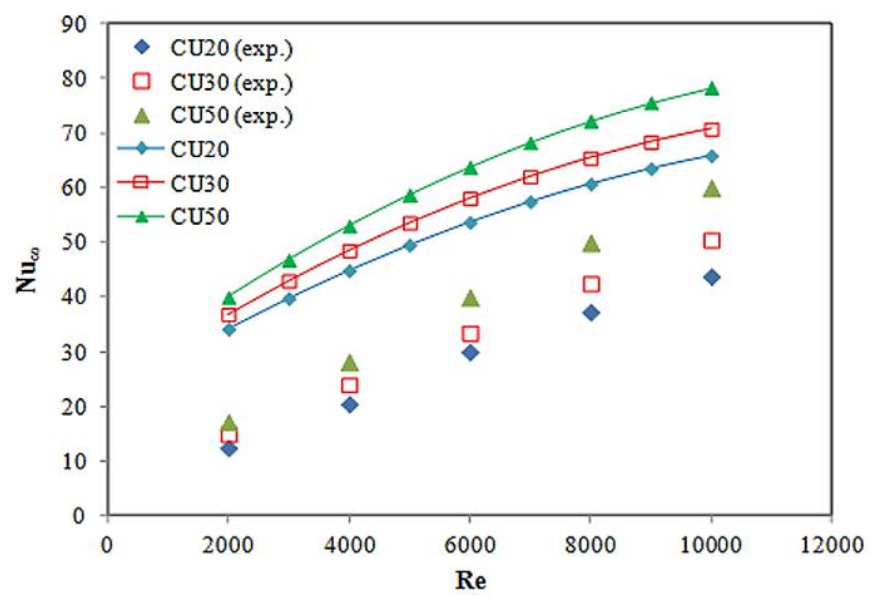

Figure 6. Comparing CFD simulation to experiment [35] for CU profile.

These figures show that our CFD simulation overestimates heat transfer coefficients. It was mentioned in the introduction that a 3D_CFD simulation of a regenerator with CU profiles overestimated the performance [9], too. The difference between experiment and CFD results becomes lower at higher Reynolds numbers. However, the differences are not still negligible at high Reynolds. For example, at $\mathrm{Re}=10000$ the CFD simulation resulted in Nusselt numbers of $50 \%, 40 \%, 30 \%$ and 56\% larger than experimental data for CU20, CU30, CU50 and DU30, respectively.

Regarding the overestimation of CFD simulation, it is predictable that the model of rotary air heater also calculates higher heat transfer between cold air and hot gas. Nevertheless, using the heat transfer and pressure drop correlations derived from CFD simulations (as Figure 5) still has advantages. They give us the opportunity of comparing the utilization of various heating surfaces (profiles) from heat transfer effectiveness and pressure drop viewpoints. It is because CFD has predicted successfully the trend of effectiveness of various heating surfaces comparing to each other (as is obvious from Figure 6).

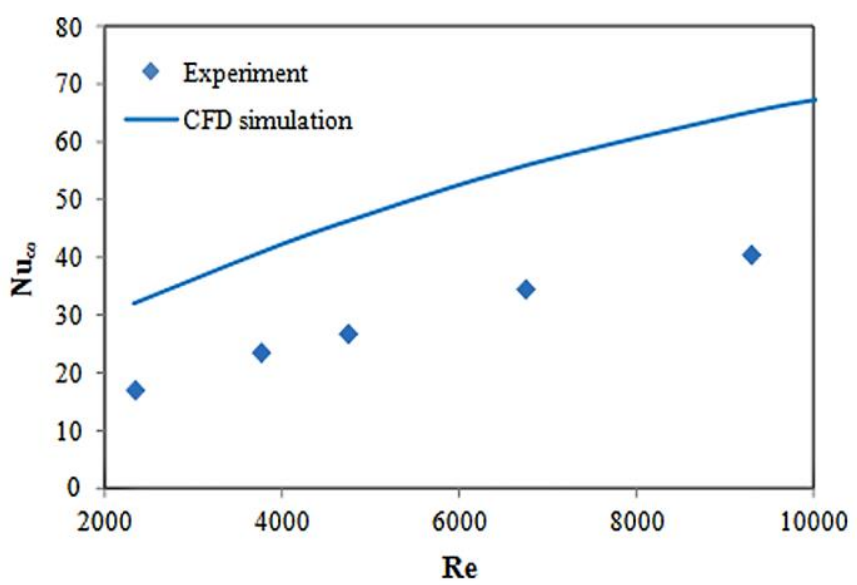

Figure 7. Comparing CFD simulation to experiment [18] for DU30 profile. 


\section{RAH Model Validation}

The model was compared with the design data of a rotary air heater in a boiler of a $320 \mathrm{MW}$ power plant. There are eight units of this boiler in Iran. So optimizing their air heaters would reduce fuel consumption and air pollution significantly. The rotor and hub diameter of the RAH are equal to 7.93 and 2.16 meters and rotational speed of the matrix is $1.4 \mathrm{rpm}$. Air flow enters the air heater at a temperature of $27^{\circ} \mathrm{C}$ and leave it at $303{ }^{\circ} \mathrm{C}$. The inlet and outlet temperatures of hot flue gas are 380 and $145^{\circ} \mathrm{C}$, respectively. The RAH is divided to three layers in flow direction: hot end layer, intermediate layer, and cold end layer. Dimensional parameters of different layers in this Ljungstrom is demonstrated in Table 2.

Table 2. Specifications of the rotary air heater layers.

\begin{tabular}{llll}
\hline & Profile & $\mathrm{D}_{\mathrm{h}}(\mathrm{mm})$ & Layer length $(\mathrm{m})$ \\
\hline hot end & DU30 & 12 & 0.8 \\
intermediate & DU30 & 12 & 0.45 \\
cold end & $\mathrm{NF}$ & 20 & 0.305 \\
\hline
\end{tabular}

The developed model was used to estimate this RAH performance. The model resulted in an air and gas outlet temperatures equal to 309 and $138.6{ }^{\circ} \mathrm{C}$. Comparing to real data, the model was capable of forecasting the thermal behavior of the RAH by an error close to $6{ }^{\circ} \mathrm{C}$. One of the most possible reasons for this overestimating could be the higher Nusselt numbers predicted by CFD simulations.

\section{Optimization Scenarios}

Optimization results are entirely dependent to the choice of objective function and constraints. These two are defined by what we want from optimization. In this study, three scenarios were considered which will be addressed as "Opt". Each one was obtained based on a different level of modifications. In other words, more changes should be implemented in the RAH in Opt3 comparing to Opt1. These three scenarios would answer to research questions in different levels of details. As was stated in the introduction, the main goal is to find out an optimized RAH and the best heating surfaces. The results are presented in this section. It is worth mentioning that in this paper, optimal hydraulic diameters of flow passages are often presented instead of porosity. It is obvious that increasing hydraulic diameter is equivalent to decreasing the porosity when the wall thickness remains constant.

The objective function is the same for all cases, but the constraints and independent variables are dissimilar. Two constraints are applied for all three scenarios. The first is restricting the optimized profile type for the cold end to NF and $\mathrm{CP} 0$. Not using the more advanced profiles is due to the ease of cleaning and avoiding the plugging of passages in the cold end layer. Second constraint is fixing the hot gas temperature entering the cold end layer. By calculating the current $\mathrm{RAH}$, it was found that the hot gas temperature is equal to $158^{\circ} \mathrm{C}$ when entering the cold end layer. This value is probably near $6^{\circ} \mathrm{C}$ lower than the real temperature due to the model error. Despite this error, the value is important because shows a temperature at which the designers decided to introduce the cold end layer. In fact, it is better to allocate thicker and corrosion resistance material for passages which are exposed to gas flow with a temperature below $158{ }^{\circ} \mathrm{C}$. Therefore, all the optimizations were performed by fixing the gas temperature at cold end layer entrance to $158 \pm 2{ }^{\circ} \mathrm{C}$. This constraint prevents an optimum design with a risk of corrosion at intermediate layer and also avoids the low efficient cold end layer to be larger than what is required.

"Optl": The first optimization was implemented to find the best profile types and hydraulic diameters for all three layers of a RAH in addition to the rotational speed. This optimization could be carried out only by replacing baskets and adjusting rotational speed. In fact, dimensions of RAH would not be changed and only the internal components would be modified. In addition, length of each layer remained unchanged. The optimization outcomes are presented at Table 3 . The fuel saving of $O p t 1$ is equal to $437 \mathrm{~kg} / \mathrm{hr}$ per RAH. Since there are 8 similar units of this power plant in Iran, applying the optimization for all of them will prevent wasting approximately more than 50,000 tons of natural gas annually.

Comparing to design values (Table 2), Opt1 suggests smaller hydraulic diameters especially for hot and intermediate layers. This is almost equal to doubling the porosity in these layers. In the literature it was claimed that increasing the porosity at center could increase the heat transfer in an RAH [4]. Present study shows that by considering pressure drop and using a non-constant Nusselt number, lower porosity at center is still beneficial. However, Table 3 also recommend a high porosity in hot end. 
Table 3. Results of three scenarios of optimization.

\begin{tabular}{lllll}
\hline & & Opt1 & Opt2 & Opt3 \\
\hline \multirow{2}{*}{ Profile type } & Hot end & FNC20 & FNC20 & FNC20 \\
& Intermediate layer & FNC20 & FNC20 & FNC20 \\
& Cold end & NF & NF & NF \\
Hydraulic diameter of & Hot end & 5.9 & 7.7 & 7.3 \\
passages (mm) & Intermediate layer & 6.2 & 8.1 & 5.5 \\
& Cold end & 18 & 20.6 & 16 \\
Length of each layer & Hot end & & & \\
(m) & Intermediate layer & 0.8 & 1.25 & 0.84 \\
& Cold end & 0.45 & 0.7 & 0.47 \\
Rotational Speed (rpm) & & 1.83 & 0.28 & 0.24 \\
RAH outer diameter (m) & & 7.93 & 1.36 & 1.17 \\
Fuel Saving (kg/hr) & & 437 & 4.93 & $\sim 10$ \\
\hline
\end{tabular}

Before explaining Table 3 completely, it is worth mentioning that in most of optimizations the FNC20 was selected by the algorithm as the premium heating surface for hot and intermediate layers. While NF performed better than CP0 in cold end layer. Only in some cases, CU30 or CP0 was selected in cold end layer. This proves that Nu/f ${ }^{1 / 3}$ which was presented at Figure 5 is not a perfect indicator for choosing appropriate heating surfaces. Because based on $\mathrm{Nu} / f^{1 / 3}$ the CP0 was better than NF, and CU30 had a better performance comparing to FNC30 in a wide range of Reynolds number.

But a question still remains: what if it was possible to change the length of hot, intermediate and cold layers? Figure 8 Shows the amount of fuel saving of the optimum sets by varying the length of only one layer while the lengths of two other layers remain unchanged. When length of hot end or intermediate layers is short, the hydraulic diameter becomes very small. The consequence is a higher flow resistance and hence a lower fuel saving. This is true for longer hot end or intermediate layer because of their significantly higher leakage flow from air to gas. Thus, there is a length that pressure drop, heat recovery and leakage ratio are in their best balance. This behavior was not observed for cold end layer at least in the studied range of lengths. These best optimums are highly desirable due to their reasonable length and hydraulic diameters. In other words, their length is not so large that causes supporting difficulties, and they are not so narrow causing plugging problems to become an everyday issue for operators.

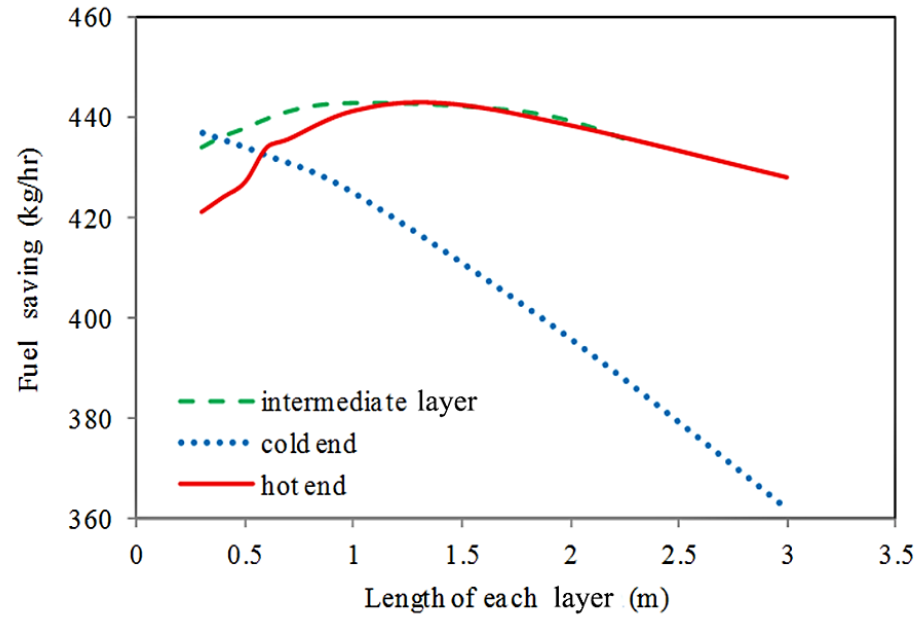

Figure 8. Fuel saving at optimum design parameters by changing length of only one layer.

"Opt2": Regarding to Figure 8, another dimension of the RAH which assumed to be constant in Opt1 was the length of each layer. Length of each layer has a straight influence on the heat transfer and pressure drop. There is a specific length at which the heat transfer and pressure drop are in their best economical balance. In Opt2, these optimum lengths were calculated. The most important issue of Opt2 is the possibility of changing the RAH length from practical viewpoint. In addition to considering available space, some extra modifications on bearing and supporting structure are also needed.

However, a simplification was employed in $O p t 2$. There was not found any specific criteria for separating the hot end from intermediate layer, like the temperature range $\left(158 \pm 2{ }^{\circ} \mathrm{C}\right)$ that was used for separating the cold end from the intermediate layer. It seems that manufacturers use two layers (hot and intermediate) instead of only one hot layer to make replacing damaged baskets easier by this modular format. Thus, this optimization performed by assuming that length of intermediate layer is proportional to length of hot end. This ratio was fixed to the current ratio $(0.45 / 0.8)$. The assumption reduced the independent parameters of Opt2 from 10 to 9. 
The final outcomes for this case did not improve fuel saving significantly, as stated in Table 3 . Heat recovery increases but with an equivalent rise in fan power. Nevertheless, $6 \mathrm{~kg} / \mathrm{hr}$ more fuel consumption was achieved by 0.675 meter increasing in overall length of the RAH. Higher value for hydraulic diameter of intermediate layer is also an advantage.

"Opt3": Further optimizing the RAH will have more modification costs while a higher value of fuel saving will be guaranteed. In Opt3, overall dimensions of RAH were also considered to be modified. These dimensions are length of each layer (cold, intermediate, hot) similar to Opt2, and outer diameter of the RAH. Obviously, these adjustments are not always applicable in a power plant due to for example lack of additional space.

Figure 9 shows the fuel saving for various optimized sets with different outer diameter of the rotary air heater. Inner diameter remained constant in these calculations. Every single point in Figure 9 was obtained by optimizing all design parameters of the RAH for a specific outer diameter. It is acceptable that increasing the frontal area (or outer diameter) should improve the performance of a regenerator [5]. A RAH with larger frontal area can transfer the same amount of heat with a lower pressure drop due to its smaller length (total surface $\sim$ frontal area $\times$ length). So in theory it is better to have a RAH with a diameter as large as it is possible. But the Figure 9 demonstrates that fuel saving becomes close to constant after an outer diameter. An optimum RAH with outer diameter equal to $19 \mathrm{~m}$ has only $2 \%$ and $19 \%$ more hourly fuel saving capability comparing to RAHs with outer diameters of $13 \mathrm{~m}$ and $10 \mathrm{~m}$, respectively.

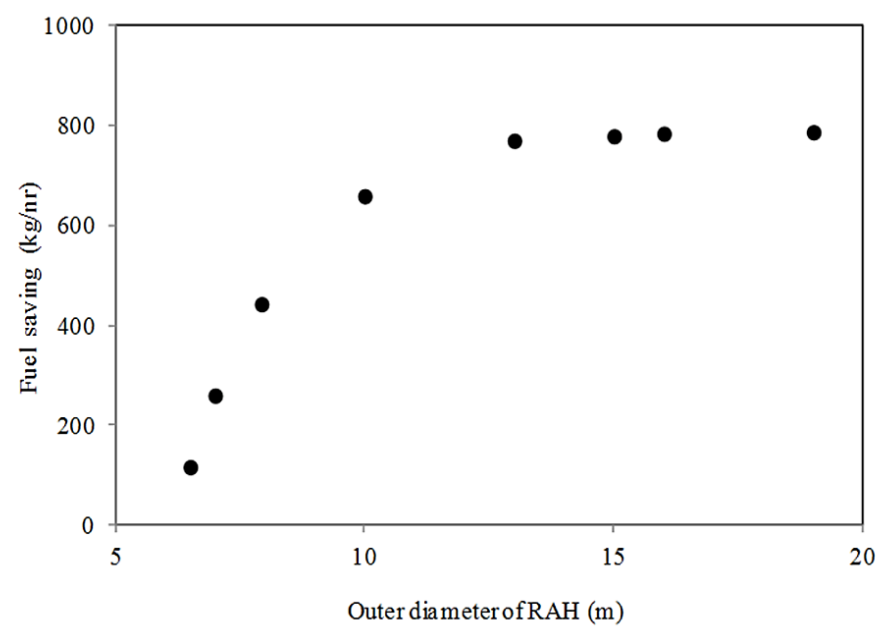

Figure 9. Fuel saving for different outer diameter of the rotary air heater (each point is an optimized case).

By moving from small to large diameters in Figure 9, optimum values of design parameters changed significantly. For example, the rotational speed dropped from 2 to 0.6 and total length of RAH fell from 2.4 to 0.25 . For a RAH with highest value of frontal area, the optimum set showed that there is even no need for a cold end layer. Another point relevant to optimum sets of Figure 9 is that the matrix passages become narrower for a bigger diameter. In other words, the optimized RAH with larger frontal area resulted surprisingly in smaller hydraulic diameters. This was perhaps to prevent the heat transfer coefficient from dropping severely. These narrow flow passages (near $3 \mathrm{~mm}$ for hot end) are not preferable because of plugging risk. From this viewpoint, a RAH with outer diameter less than $10 \mathrm{~m}$ is more acceptable due to higher hydraulic diameters (bigger than $7 \mathrm{~mm}$ ) of hot end layer.

From practical point of view, changing the outer diameter of a RAH of an existing power plant is impossible in most of cases. In addition to lack of sufficient space, a bigger RAH may experiences a large amount of air leakage, changes in driving motor requirements, problem of bending the structure especially at the circumference, and new bearing considerations. The optimum RAH with a diameter of $19 \mathrm{~m}$ (right point in Figure 9) resulted in a leakage more than $20 \%$ of the air flow that is a huge value for design point. In addition, an optimum RAH with an outer diameter equal to $16 \mathrm{~m}$ is 2.3 times heavier than an optimum RAH with an outer diameter of $7.93 \mathrm{~m}$ (current value). Furthermore, a large outer diameter is equivalent to high moment of inertia for rotary regenerator. By considering the relation of kinetic energy of a rotating cylinder, the optimum RAH with outer diameter of $19 \mathrm{~m}$ requires 5.6 times more energy to reach its rotating speed comparing with the optimum RAH with diameter of $7.93 \mathrm{~m}$. Thus a stronger driving motor may be necessary.

The optimal outer diameter for the rotary air heater discussed in this article still needs an engineering decision. But keeping these energy indicators and practical issues in mind, it seems that optimum outer diameter of this RAH should be close to $10 \mathrm{~m}$. A 10 meter rotary air heater would decrease fuel consumption significantly while leakage will be low enough (almost 2\% higher than optimum RAH with diameter of $7.93 \mathrm{~m}$ ), weight will increase slightly, required energy for reaching design speed from no-speed will be only $50 \%$ higher, and the hydraulic diameter will not be too small.

\section{Parametric Study}

In this section, influences of some parameters on the optimized RAH are discussed. Because a unique value for optimum outer diameter could not be chosen (just close to $10 \mathrm{~m}$ ), this section studied the effect of parameters on "Opt2" with a fixed outer diameter of $7.93 \mathrm{~m}$. Changing the power plant's efficiency, ambient temperature, hot gas temperature and air mass flow rate were considered. 


\section{Efficiency of the power plant}

As was stated in the method section, fan power consumption was divided by power plant's efficiency to make it possible comparing it with recovered heat. For all calculations, the efficiency was assumed to be $40 \%$. Now, it is valuable to check how the efficiency can influence the optimization. It is logical that decreasing the unit's efficiency increases the cost of fan power comparing to thermal energy. Therefore, a smaller pressure drop at lower unit's efficiency should be more desirable to reduce the fan work. Reviewing the results indicates that wider matrix passages are chosen in optimization process. In fact, at smaller efficiencies of power plant, pressure drop of optimum set was lowered by bigger hydraulic diameters and shorter total length of regenerator. But the interesting point is that fuel saving at the optimal case did not changed for power plant's efficiencies from $30 \%$ to $45 \%$. In other words, reducing a multi objective optimization to a single objective optimization problem by introducing a "fuel saving" parameter, did not influence the fuel saving. However, different power plant's efficiencies result in different optimum sets of design parameters. These sets are equivalent to Pareto Optimal Solutions if the problem was considered by maximizing effectiveness and minimizing pressure drop with a multi objective approach. The optimal sets are presented at Table 4.

Table 4. Optimum sets for different power plant's efficiency.

\begin{tabular}{lcccc}
\hline$\eta(\%)$ & 30 & 35 & 40 & 45 \\
\hline $\mathrm{Q}(\mathrm{kW})$ & 52164 & 52218 & 52488 & 52751 \\
Fan $(\mathrm{kW})$ & 1701 & 1710 & 1816 & 1936 \\
Fuel saving (kg/hr) & 444 & 444 & 443 & 444 \\
Leakage (\%) & 9.99 & 9.94 & 10.27 & 10.34 \\
Speed (rpm) & 1.5 & 1.45 & 1.36 & 1.48 \\
$\mathrm{D}_{\mathrm{h}}$ hot $(\mathrm{mm})$ & 7.3 & 7.7 & 7.7 & 7 \\
$\mathrm{D}_{\mathrm{h}}$ mid (mm) & 7.7 & 7.8 & 8.1 & 7.9 \\
$\mathrm{D}_{\mathrm{h}}$ cold (mm) & 24.1 & 18.2 & 20.6 & 21.5 \\
Profile_hot & FNC20 & FNC20 & FNC20 & FNC20 \\
Profile_mid & FNC20 & FNC20 & FNC20 & FNC20 \\
Profile_cold & $\mathrm{NF}$ & $\mathrm{NF}$ & $\mathrm{NF}$ & $\mathrm{NF}$ \\
L hot+mid (m) & 1.65 & 1.8 & 1.95 & 1.85 \\
L cold (m) & 0.37 & 0.19 & 0.28 & 0.38 \\
\hline
\end{tabular}

\section{Ambient air temperature}

Air temperature entering a rotary air heater is an important parameter in designing a RAH. In particular, it has a direct effect on geometry of cold end layer. It is expected that higher ambient temperatures decrease the thermal load and so the size of required regenerator. In this section, influence of cold air temperature on optimum values of design parameters was studied. Figure 10 summarized the results. The optimal rotational speed for a RAH working in a hot climate is slightly higher (Figure 10a). In this situation, flow leakage also decreases which is a merit. Total heat transfer reduces for higher ambient temperatures (Figure 10d). As a consequence, because optimum fan power almost did not change, the potential of fuel saving declines.

As mentioned earlier, in our calculations, hot gas temperature at the entrance of cold end layer was fixed to avoid a poor design which causes an acid corrosion in matrix. Therefore, as seen in Figure 10c, a considerable reduction in optimum length of cold end layer has occurred at high ambient temperatures. Whereas, a decrease in optimal hydraulic diameter is evidenced, too (Figure 10b). However, for the highest air temperature, hydraulic diameter of cold end layer rises suddenly. This sudden enlargement in $\mathrm{D}_{\mathrm{h}}$ of cold layer happened because the need for a cold end layer decreased as the risk of acidic corrosion was reduced. In these conditions, cold end reached to its lower limit of length (see optimization sub-section in method section) and genetic algorithm increased the hydraulic diameter instead. Of course, the same reduction in length and a minor drop in hydraulic diameters are observable for hot and intermediate layers, too.

In summary, when a rotary regenerator works in a cold or hot climate it is better to change some design parameters to make the highest benefit from it. Eight similar units in Iran that use this type of RAH are located near three cities each of them has a different climate. Redesigning their RAH based on most frequent ambient temperature would lead to a big difference in fuel saving. This is observable in Figure 10 that air temperature can influence the optimal values of all considered design parameters (rotational speed, hydraulic diameters and length of all three layers) remarkably. 

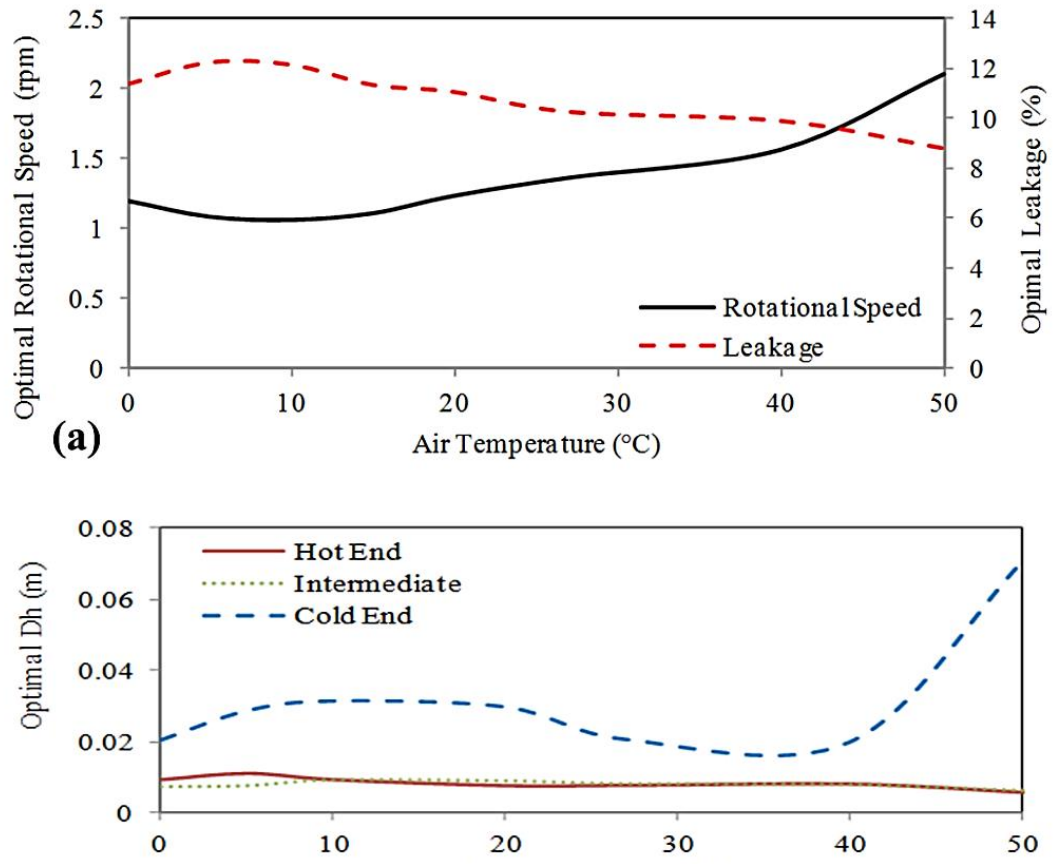

(b)

Air Tempera ture $\left({ }^{\circ} \mathrm{C}\right)$

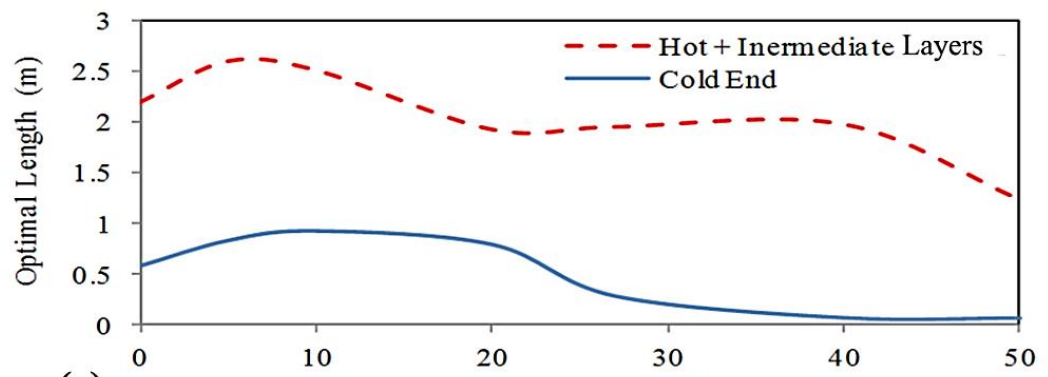

(c)

Air Tempera ture $\left({ }^{\circ} \mathrm{C}\right)$

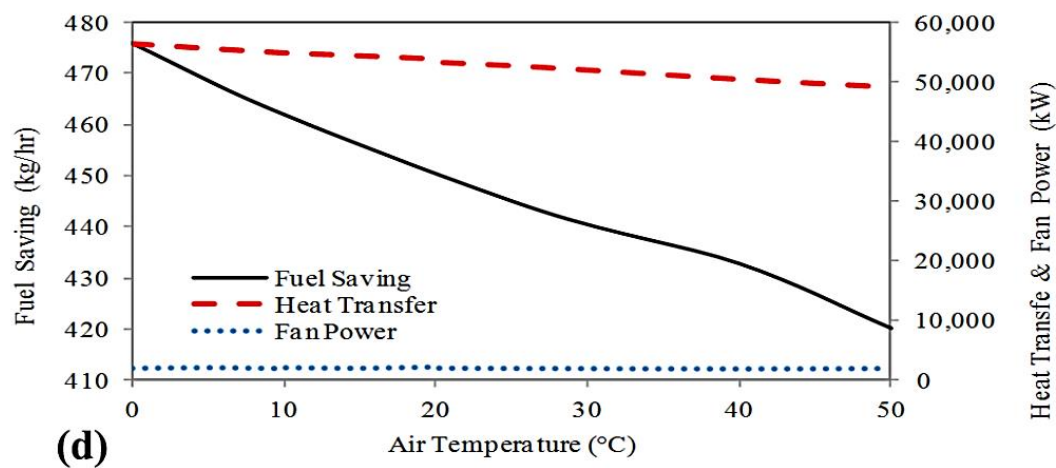

Figure 10. Variation of optimal parameters vs. ambient temperature. (a) rotational speed and leakage flow, (b) hydraulic diameters of hot, intermediate, and cold layers, (c) length of hot+intermediate and cold layers, (d) total recovered heat, fan power, and fuel saving. 

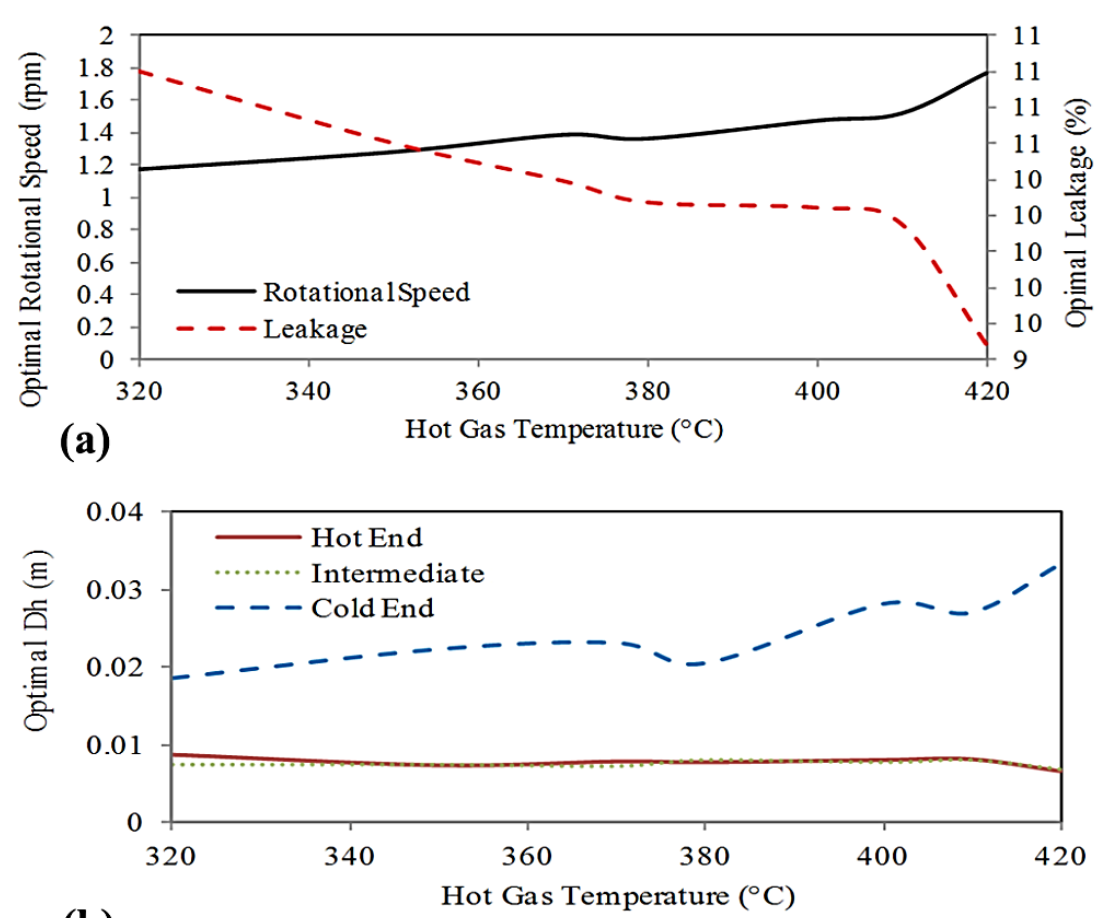

(b)

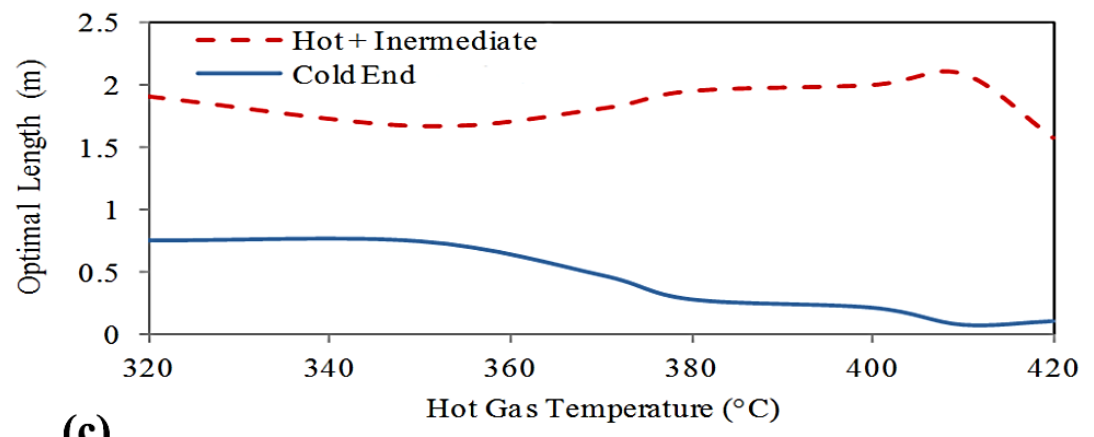

(c)

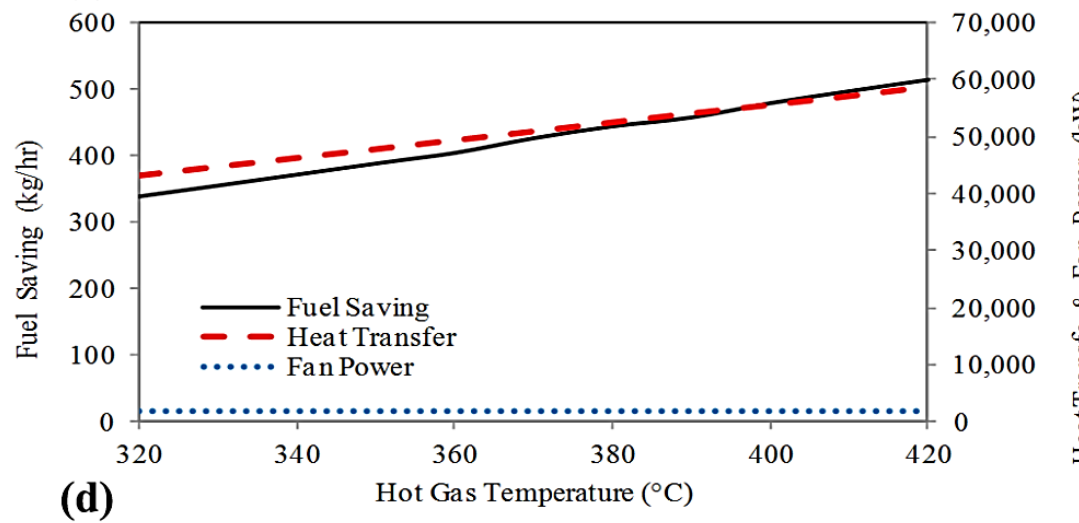

Figure 11. Variation of optimal parameters vs. hot gas temperature. (a) rotational speed and leakage flow, (b) hydraulic diameters of hot, intermediate, and cold layers, (c) length of hot+intermediate and cold layers, (d) total recovered heat, fan power, and fuel saving.

\section{Hot gas temperature}

Temperature of hot gas entering a RAH is also very determinative. In fact, this temperature is a direct indicator of heat recovery potential or thermal load of the heat exchanger. Figure 11 shows the results of changing hot gas temperature. As it was expected, total heat transfer from hot gas to cold air increased. Hence the fuel saving was raised (Figure 11d). Leakage drops at higher inlet gas temperatures. Optimum rotational speed gradually increased by rising the gas temperature (Figure 11a).

In general, higher temperature of gas means that the risk of acidic corrosion is lower. This is reflected at Figure 11c where length of cold layer dropped for a hotter inlet gas. In fact, by increasing the inlet gas temperature, gas will reach later to $158^{\circ} \mathrm{C}$ (which was used to find the beginning of cold end layer) and the cold end layer will be shorten. Therefore, 
when temperature of hot gas is larger, it is better to use a shorter cold end layer with wider flow channels. Characteristics of hot end and intermediate layers were not influenced notably.

In general, if the hot gas temperature increases permanently (for example due to malfunction of burners, economizers or superheaters), an increase in rotational speed and reducing the length of cold end while its flow passages become wider helps to attain an optimum heat recovery.

\section{Mass flow rate of air}

Another parameter which can determine the thermal load of a RAH is mass flow rate of inlet air. In power plant applications, this value is obtained from required air for combustion in boiler. Here, a natural gas fired boiler was assumed with an excess air equal to $10 \%$. Afterwards, the hot gas flow rate was also calculated from mass flow rate of inlet air.

As it is obvious from Figure 12d, by increasing the air mass flow rate from 100 to $200 \mathrm{~kg} / \mathrm{s}$, total heat transfer doubles while the pressure drop becomes 3.5 times higher. The net effect is the increasing of fuel saving by air mass flow rate a little weaker than what happened for total heat transfer. Meanwhile, leakage percentage falls down from near $13.5 \%$ to $9 \%$ and optimal rotational speed oscillates between 1.25 and 1.55 (Figure 12a). It is worth noting that increasing the air mass flow rate for a fixed RAH leads to a lower efficiency [7]. Fuel saving increasing that is presented in Figure 12 has a different meaning. In fact, an optimization had performed for every single value of air flow rate. So by increasing the air flow rate, the design of RAH has been changed.

Figure $12 \mathrm{~b}$ shows that increasing the mass flow rates from 100 to $200 \mathrm{~kg} / \mathrm{s}$ by keeping constant the other parameters of a RAH (i.e. outer diameter, inlet temperature of air and hot gas), results in hydraulic diameters 1.5 and 2.2 times bigger for hot and intermediate layers, respectively. While the $\mathrm{D}_{\mathrm{h}}$ of flow passage at cold end layer remains close to $22 \mathrm{~mm}$. The same pattern is detectable for optimum length of layers (Figure 12c).

In general, if the air flowing to a boiler changes permanently (for example by aging or switching to a new fuel), it is recommended to adopt the hydraulic diameters and lengths of hot and intermediate layers to improve the RAH from energy viewpoint. It is also a good guidance for designing a new RAH for power plants that are a little smaller or bigger than the discussed case. Of course, optimal outer diameter remained constant in these calculations.

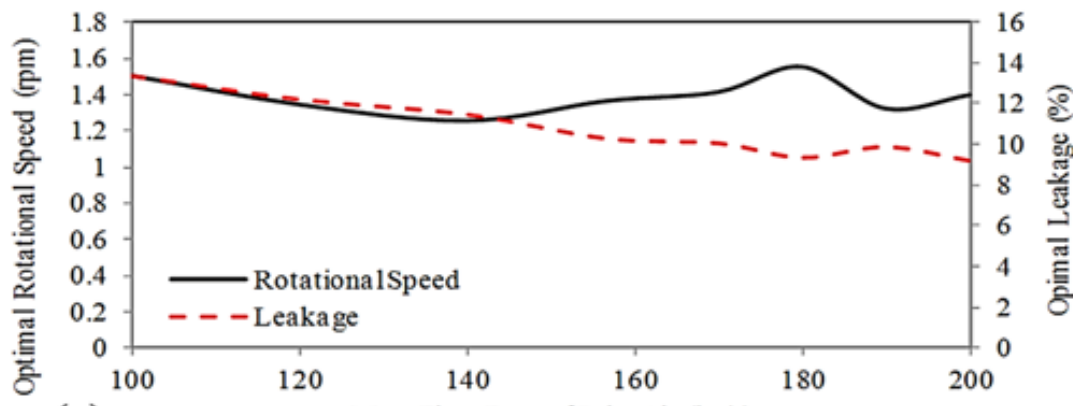

(a) Mass Flow Rate of Inlet Air $(\mathrm{kg} / \mathrm{s})$

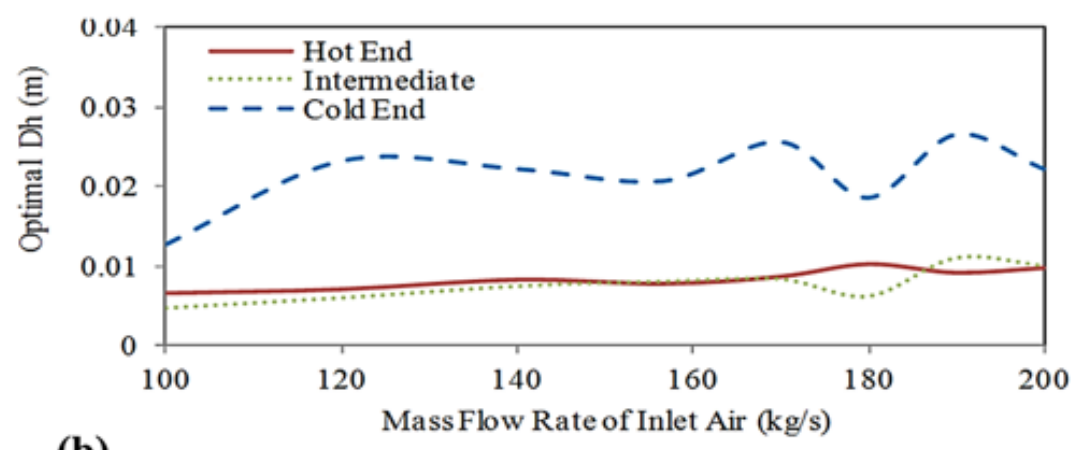

(b) 


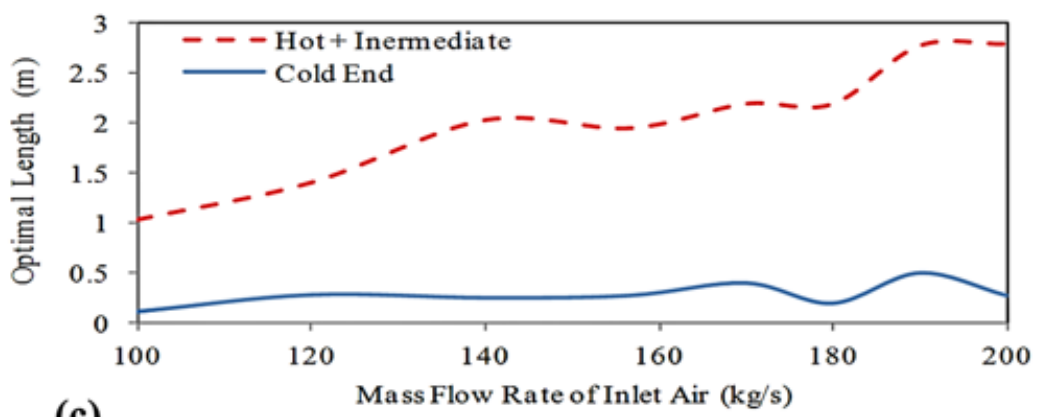

(c)

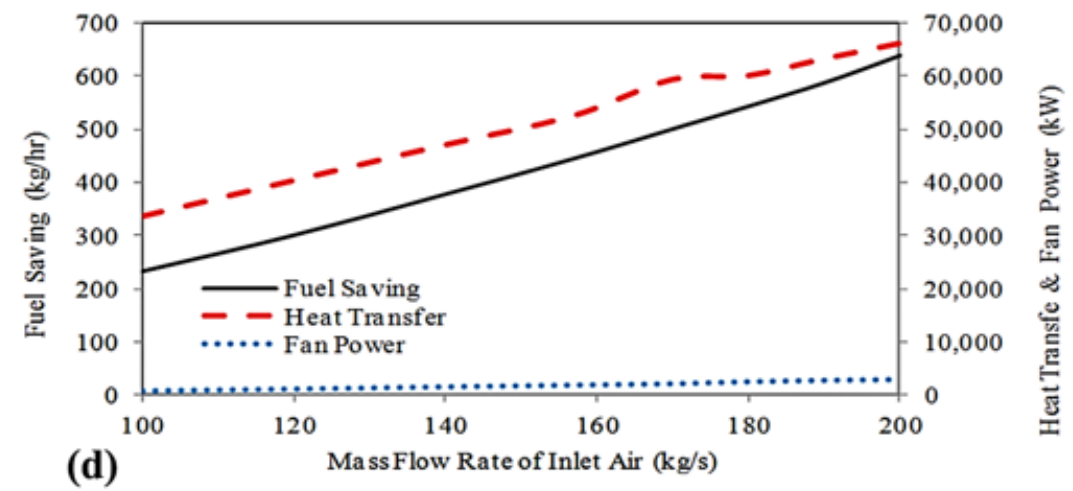

Figure 12. Variation of optimal parameters vs. mass flow rate of air. (a) rotational speed and leakage flow, (b) hydraulic diameters of hot, intermediate, and cold layers, (c) length of hot+intermediate and cold layers, (d) total recovered heat, fan power, and fuel saving.

\section{CONCLUSION}

Rotary air heaters (RAH) are simple equipment which are popular in power plants or air conditioning applications. They can improve thermal efficiency of systems by recovering heat content of flue gas. Thus, optimizing their design parameters could minimize wasting the energy. In this paper, a rotary regenerator was modeled by combining mathematical modeling and CFD simulations. Three dimensional CFD was implemented to find out the heat transfer and pressure drop through 5 types of heating surfaces by considering various inclination angles (13 flow passage in total). Then the RAH was modeled mathematically using the correlations for heat transfer and friction factor derived from CFD. Three layers of a regenerator (hot end, intermediate, cold end) were taken into account by assigning specific geometrical parameters to each of them. Afterward, the RAH was optimized by genetic algorithm and optimal design parameters were obtained (i.e. rotational speed, and heating surfaces/hydraulic diameters/lengths for all three layers).

To optimize a rotary regenerator, it is required to maximize the heat transfer while minimizing pressure drop. These two parameters are in conflict, so multi objective optimization is usual. However, a single optimization was used in this article by introducing a fuel saving parameter that reflects both pressure drop and heat transfer. The optimization was performed by assuming three scenarios. In the first one (called opt1), the RAH was optimized by changing the types and hydraulic diameters of heating surfaces and the rotational speed. Second scenario (opt2) optimized the length of each layer in the RAH in addition to the previous parameters. In the third scenario (opt3), the outer diameter was also optimized. Finally, influence of power plant's efficiency, cold air temperature, hot gas temperature and air mass flow rate were discussed on the optimum RAH. Main findings of this paper could be pointed as below:

(1) Optimizing the RAH will save 437, 444, and $660 \mathrm{~kg}$ of natural gas at one hour for only one rotary air heater for opt1, opt2, and opt3, respectively. The highest fuel saving needs major changes in power station which may be impractical but replacing the matrix baskets with suggested optimum heating surfaces is completely practical.

(2) Although plotting $N u / f^{1 / 3}$ for different flow channels showed that corrugated undulated (CU) is the best heating surface for all considered Reynolds numbers, in most of optimization sets the FNC (flat notched crossed) was preferred for hot and intermediate layers. For cold end, only two passages were considered due to ease of cleaning: notched flat (NF) and a straight corrugated plate (CP0). In most of cases the NF was selected by optimization algorithm maybe for its significantly lower pressure drop.

(3) Increasing the outer diameter of a rotary regenerator is not necessarily equivalent to improvement in performance of it. In fact, the fuel saving does not change after a specific outer diameter. Regarding the problems with large outer diameters which were mentioned in the article, optimized RAH with an outer diameter close to $10 \mathrm{~m}$ (instead of $7.93 \mathrm{~m}$ ) could intensify the amount of fuel saving significantly.

(4) When the RAH works at higher ambient temperature or air inlet temperature was increased by a steam preheater, the fuel saving potential decreases. However, the risk of acidic corrosion reduces. In higher air temperatures, it is 
recommended to design a rotary regenerator with higher rotational speed, shorter hot and intermediate layers while diminishing the cold end layer (increasing its hydraulic diameter and reducing its length).

(5) Influence of increasing the hot gas temperature, due to any permanent change in operation of boiler, leads to improvement in fuel saving if the RAH was redesigned to new optimum design values. The optimal RAH for higher hot gas temperature has a little higher rotational speed and a shorter cold end layer. Other parameters does not change significantly.

(6) Increasing the mass flow rate of air flow resulted obviously in better fuel saving. Keeping in mind that hot gas flow was also changed based on calculating required air for combustion of natural gas, some changes are suggested. In this case, hydraulic diameters and length of hot end and intermediate layers should be increased to remain at optimum conditions.

The optimization method and these findings could be used widely by design engineers and also operational engineers of power plants to boost thermal efficiency of power units. For future activities, it is recommended to set up an experiment to measure accurate values for heat transfer and pressure drop through various heating surfaces. This would increase the reliability of results from quantitatively point of view.

\section{REFERENCES}

[1] Warren I. Ljungstrom heat exchangers for waste heat recovery. Journal of Heat Recovery Systems. 1982; 2(3): $257-271$.

[2] Alhusseny A, Turan A. An effective engineering computational procedure to analyse and design rotary regenerators using a porous media approach. International Journal of Heat and Mass Transfer. 2016; 95: 593-605.

[3] Cravero C, Spoladore A. Transient Numerical Simulation of Regenerative Systems with Waste Gas Recirculation Strategies in Glass Production Plant. Applied Sciences. 2019; 9(7): 1496.

[4] Dallaire J, Gosselin L, Da Silva AK. Conceptual optimization of a rotary heat exchanger with a porous core. International Journal of Thermal Sciences. 2010; 49(2): 454-462.

[5] Duprat F, Lopez Lopez G. Comparison of performance of heat regenerators: relation between heat transfer efficiency and pressure drop. International journal of energy research. 2001; 25(4): 319-329.

[6] Fathieh F, et al. Effects of heat loss/gain on the transient testing of heat wheels. Journal of Thermal Science and Engineering Applications. 2016; 8(3): 031003.

[7] Heidari-Kaydan A, Hajidavalloo E. Three-dimensional simulation of rotary air preheater in steam power plant. Applied Thermal Engineering. 2014; 73(1): 399-407.

[8] Kilkovský B, Jegla Z. Preliminary Design and Analysis of regenerative heat exchanger. Chemical engineering transactions. 2016; 52: 655-660.

[9] Liang $\mathrm{Hw}, \mathrm{Xu} \mathrm{Zg.} \mathrm{Three-dimensional} \mathrm{modeling} \mathrm{method} \mathrm{for} \mathrm{heat} \mathrm{exchange} \mathrm{of} \mathrm{rotary} \mathrm{air} \mathrm{preheater} \mathrm{in} \mathrm{coal-fired} \mathrm{power} \mathrm{plant.}$ Heat Transfer-Asian Research. 2011; 40(1): 37-48.

[10] Mandegari MA, Farzad S, Pahlavanzadeh H. Exergy performance analysis and optimization of a desiccant wheel system. Journal of Thermal Science and Engineering Applications. 2015; 7(3): 031013.

[11] Mioralli P, Ganzarolli M. Thermal analysis of a rotary regenerator with fixed pressure drop or fixed pumping power. Applied Thermal Engineering. 2013; 52(1): 187-197.

[12] Özdemir K, Serincan MF. A computational fluid dynamics model of a rotary regenerative heat exchanger in a flue gas desulfurization system. Applied Thermal Engineering. 2018; 143: 988-1002.

[13] Roetzel W, Ranong CN. Thermal calculation of heat exchangers with simplified consideration of axial wall heat conduction. in: E3S Web of Conferences. EDP Sciences;2018.

[14] Seo J-W, Lee D-Y, Kim D-S. A simple effectiveness model for heat wheels. International Journal of Heat and Mass Transfer. 2018; 120: 1358-1364.

[15] Tong Y, et al. The study on heat transfer model and algorithm of multi-sectional regenerative air heater in power plant boiler based on analytical method. in: Applied Mechanics and Materials. Trans Tech Publ;2014.

[16] Yadav A, Yadav L. Comparative performance of desiccant wheel with effective and ordinary regeneration sector using mathematical model. Heat and Mass Transfer. 2014; 50(10): 1465-1478.

[17] Yilmaz T, Büyükalaca O. Design of regenerative heat exchangers. Heat transfer engineering. 2003; 24(4): 32-38.

[18] Zhang L, Che D. An experimental and numerical investigation on the thermal-hydraulic performance of double notched plate. Journal of Heat Transfer. 2012; 134(9): 091802.

[19] Zhang X, et al. Estimation of the direct leakage of rotary air preheaters based on temperature distribution modeling. International Journal of Heat and Mass Transfer. 2019; 134: 119-130.

[20] Wang L, et al. Single and multi-objective optimizations of rotary regenerative air preheater for coal-fired power plant considering the ammonium bisulfate deposition. International Journal of Thermal Sciences. 2019; 136: 52-59.

[21] Ghodsipour N, Sadrameli M. Experimental and sensitivity analysis of a rotary air preheater for the flue gas heat recovery. Applied Thermal Engineering. 2003; 23(5): 571-580.

[22] Kays WM, London AL. Compact heat exchangers. 1984. 
[23] Raja BD, Jhala R, Patel V. Multi-objective optimization of a rotary regenerator using tutorial training and self-learning inspired teaching-learning based optimization algorithm (TS-TLBO). Applied Thermal Engineering. 2016; 93: 456-467.

[24] Gilani S, Al-Kayiem H, Woldemicheal D. Effect of conical pin arrangement on heat transfer efficiency of a free convective solar air heater. Journal of Mechanical Engineering and Sciences. 2016; 10: 2053-64.

[25] Ma'arof M, et al. Influence of fins designs, geometries and conditions on the performance of a plate-fin heat exchangerexperimental perspective. Journal of Mechanical Engineering and Sciences . 2019; 13(1): 4368-4379.

[26] Menni Y, Azzi A, Chamkha A. Optimal thermo aerodynamic performance of s-shaped baffled channels. Journal of Mechanical Engineering and Sciences. 2018; 12(3): 3888-3913.

[27] Kwiczala AM, et al. Hybrid techology of flue gas denitrification system. Part 1-Preliminary studies of flow turbulence and pressure drop in the elements of rotary air heater baskets. Journal of Power Technologies. 2019; 99(2): 98.

[28] Abroshan H. Numerical simulation of turbulent flow and heat transfer though sinusoidal ducts. Heat and Mass Transfer. 2018; 54(7): 2045-2059.

[29] Patel DS, Patel MD, Thakkar SA. To optimize the design of the basket profile in Ljungstrom air preheater. International Research Journal of Engineering and Technology (IRJET). 2016; 3(5): 6.

[30] Bergman TL, et al. Fundamentals of heat and mass transfer. John Wiley \& Sons, 2017, p. 533-534.

[31] Shah RK, Sekulic DP. Fundamentals of heat exchanger design. John Wiley \& Sons, 2003, p. 360-366.

[32] Skiepko T. Indirect estimation of leakage distribution in steam boiler rotary regenerators. Heat transfer engineering. 1997; 18(1): 56-81.

[33] Shah R, Skiepko T. Influence of leakage distribution on the thermal performance of a rotary regenerator. Applied Thermal Engineering. 1999; 19(7): 685-705.

[34] Migai V. Regenerative rotary air preheaters. Energia, Leningrad. 1971.

[35] Stasiek J. Experimental studies of heat transfer and fluid flow across corrugated-undulated heat exchanger surfaces. International Journal of Heat and Mass Transfer. 1998; 41(6-7): 899-914.

[36] Sadrameli S. Mathematical models for the simulation of thermal regenerators: A state-of-the-art review. Renewable and Sustainable Energy Reviews. 2016; 58: 462-476. 